\title{
Moodle-fólio para o ensino em saúde e enfermagem: avaliação do processo educacional
}

\author{
Moodle-folio for teaching in health and nursing: an evaluation of the educational process
}

Moodle-folio para la enseñanza en salud y enfermería: evaluación del proceso educacional

Elioenai Dorneles Alves ${ }^{1}$, Lísia Sousa Neiva Ribeiro², Débora Caetano de Souza Martins Guimarães ${ }^{3}$, Cássio Murilo Alves Costa ${ }^{4}$, Henry Maia Peixoto ${ }^{5}$, Emerson Fachin Martins ${ }^{6}$, Aline Oliveira Silveira ${ }^{7}$

\section{RESUMO}

A educação a distância organizada a partir de ambientes virtuais de aprendizagem tem se constituído com uma realidade em expansão na formação de profissionais de saúde no Brasil. Nesta perspectiva, a Universidade de Brasília vem utilizando uma proposta pedagógica inovadora. Dessa maneira, o presente estudo de caso descreveu o uso de um portfólio eletrônico nos processos de ensino e aprendizagem utilizados em duas disciplinas de graduação e em uma de pós-graduação. Foram coletados dados a partir da observação direta e registro das disciplinas e das respostas de 270 alunos a um questionário. Os resultados indicaram um significativo grau de satisfação dos estudantes sobre o design instrucional usado, assim como o caráter inovador da proposta. Portanto, o uso do referido portfólio foi considerado satisfatório quanto aos aspectos capazes de apoiar o processo ensino-aprendizagem a distância na área da saúde.

Descritores: Avaliação Educacional; Educação a Distância; Educação Superior; Enfermagem.

\section{ABSTRACT}

Distance education organized by means of virtual learning environments is a current reality in the expansion of the education of health professionals in Brazil. In this perspective, The University of Brasilia has been using an innovative educational proposal. Therefore, the present case study describes the utilization of an electronic portfolio in the teaching and learning process of two undergraduate and one graduate classes. Data were collected based on direct observation of the classes and on the answers to a questionnaire completed by 270 students. The results showed a significant level of satisfaction among the students regarding the instructional design in use, as well as the innovative character of the proposal. Therefore, the use of the portfolio was considered satisfactory in terms of supporting the teaching-learning process in distance education within the healthcare field.

Descriptors: Educational Measurement; Education, Distance; Education, Higher; Nursing.

\section{RESUMEN}

La educación a distancia organizada desde ámbitos virtuales de aprendizaje se ha constituido en una realidad en expansión en la formación de profesionales de salud en Brasil. En dicha perspectiva, la Universidad de Brasília viene utilizando una propuesta pedagógica innovadora. El presente estudio de caso describió el uso de un portfolio electrónico en los procesos de enseñanza y aprendizaje utilizados en dos disciplinas de grado y en una de posgrado. Datos recolectados mediante observación directa y registro de las disciplinas y de las respuestas de 270 alumnos a un cuestionario. Los resultados indican un significativo grado de satisfacción de los estudiantes sobre el diseño de instrucción utilizado, así como el carácter innovador de la propuesta. Consecuentemente, el uso del referido portfolio fue considerado satisfactorio en cuanto a los aspectos capaces de apoyar el proceso de enseñanza-aprendizaje a distancia en el área de la salud.

Descriptores: Evaluación Educacional; Educación a Distancia; Educación Superior; Enfermería.

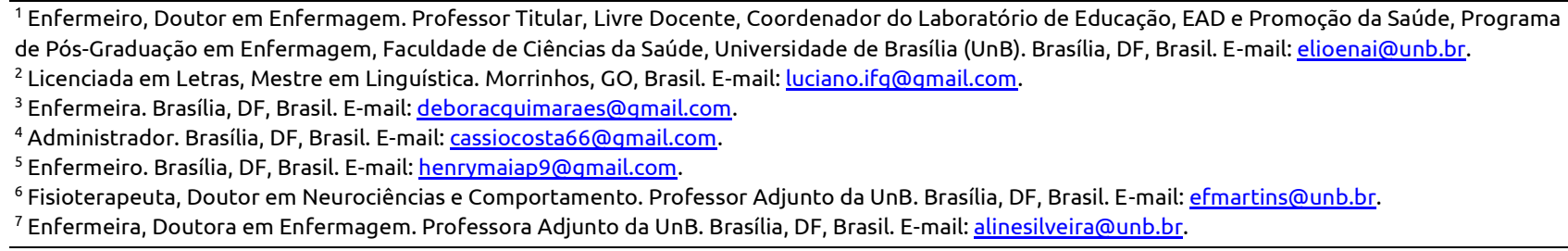




\section{INTRODUÇÃO}

Desde a década de 90, professores do Departamento de Enfermagem da Universidade de Brasília - UnB tem utilizado o desenho padrão de um portfólio que tem contribuído para o processo de avaliação de disciplinas de graduação dentro de um modelo tradicional de ensino(1-4).

Os portfólios utilizados nos ambientes virtuais de aprendizagem (AVA), que analisaremos neste artigo, serão denominados de Moodle-fólios, definidos como o conjunto de registros de etapas e fases, experiências vivenciadas como processos e produtos da aprendizagem on-line, que foram acompanhadas pelos docentes e tutores responsáveis pela supervisão do espaço virtual e que integram o grupo cadastrado no diretório de pesquisa do $\mathrm{CNPq}$ com o nome de Laboratório de Educação, Educação a Distância (EAD) e Promoção da Saúde - LEPS, que desde sua criação em 2002, passaram a utilizar a ferramenta Moodle, preconizada na UnB como ambiente disponível para todas as disciplinas de graduação.

O espaço http://aprender.unb.br, que hospeda oficialmente todas as disciplinas, cursos e atividades extensionistas da UnB, foi utilizado para garantir uma maior segurança aos registros e documentos que fornecem subsídios para o acompanhamento e avaliação do processo de ensino-aprendizagem. Ainda, dentre as vivências e produtos deste grupo, destacamos a utilização do Moodle como hospedagem para nossos portfólios eletrônicos individuais e coletivos. Tais portfólios têm funcionado como registros dos processos e produtos desenvolvidos em situações de formação de professores, como cursos de extensão para capacitação de tutores e monitores para supervisão em e-learning na área de saúde; e como ambiente para oferta de disciplinas de graduação e pós-graduação em saúde desde 2001, destacando-se o reconhecimento internacional do design proposto nessas vivências ${ }^{(1)}$.

Nesta perspectiva, compreendemos que os AVA estão postos como a expressão do incrível avanço tecnológico que tem circundado a sociedade nos últimos séculos, os AVA são salas de aula virtuais acessadas via web. A função dos AVA seria diminuir a distância física e estreitar a comunicação entre os participantes de um curso ministrado neste ciberespaço(5). Ainda, ao que parece, a distância física não chega a afetar de modo considerável o desempenho dos alunos envolvidos em um processo educativo mediado por um ambiente virtual ${ }^{(6-9)}$.

Com a introdução das novas tecnologias de comunicação, os espaços restritos e fixos das salas de aula convencionais, bem como o contato físico diário proporcionado por eles, são substituídos por outras formas possíveis de se desenvolver o ensino, que por meio de encontros virtuais em listas de discussão, chats e videoconferências, oportuniza novos momentos de interação, nos quais pode haver o compartilhamento de conhecimentos e de informações de modo mais intenso do que nas aulas presenciais ${ }^{(8)}$.

Isso demonstra que nas comunidades virtuais de aprendizagem, alunos e professores não estão mais condicionados a um espaço predeterminado e a horários rígidos e de que, os AVA, quando bem utilizados fazem com que a distância física seja amenizada por meio da comunicação entre aqueles que aprendem e aqueles que ensinam ${ }^{(9)}$.

Nesse contexto, destacamos a escolha do AVA Moodle, como exemplo de um Learning Management System (LMS), um tipo de ambiente virtual constituído de várias funcionalidades que facilitam o gerenciamento de um curso a distância via Web, que viabiliza a comunicação entre seus participantes e auxilia na organização de conteúdos $^{(9-10)}$. Portanto, sua utilização se justifica pelo fato de ser uma plataforma de código aberto, livre e gratuito ${ }^{(7,9)}$, além de ser mais comumente usado na EAD. Ademais, o Moodle possibilita a criação de grupos entre os membros de um determinado curso, sendo esta funcionalidade de extrema relevância quando se quer delegar aos grupos tarefas específicas na elaboração colaborativa de um trabalho.

Para o desenvolvimento de atividades em grupo nos AVA é necessário que tais ambientes incorporem a sua estrutura organizacional e funcional ferramentas colaborativas e interativas. Nesta perspectiva, o Moodle viabiliza um conjunto de ferramentas síncronas e assíncronas, as quais se classificam como: fórum, tarefas, edição colaborativa, banco de dados, glossário, questionário, pesquisa de opinião, trabalho com revisão, pesquisa de avaliação e bate-papo ${ }^{(5,10)}$.

Esta variedade de ferramentas disponibiliza ao professor a oportunidade de explorar os diferentes estilos de aprendizagem dos alunos ${ }^{(5)}$. Tendo tantos recursos ao seu alcance, o professor pode utilizar-se deles para personalizar suas aulas de forma que 
ofereçam aos alunos o exercício da sua autonomia enquanto escrevem ou discutem os fóruns, quando participam dos bate-papos e quando trabalham em grupo ou individualmente ${ }^{(5)}$.

Mediante o exposto, o presente estudo teve como objetivo analisar o uso do moodle-fólio, nos processos de ensino e aprendizagem utilizados em disciplinas de graduação e pós-graduação, na área da saúde na Universidade de Brasília.

\section{MÉTODO}

Estudo de caso, cujo objeto de estudo foi o processo de desenvolvimento de duas disciplinas de graduação e uma de pós-graduação, ofertadas a alunos da área de saúde e ministradas sob a coordenação do NESPROM (Núcleo de Estudos em Educação, Promoção da Saúde e Projetos) com aval da Universidade de Brasília (UnB) na modalidade EAD.

Participaram do estudo alunos de graduação e pósgraduação matriculados nas referidas disciplinas. Foram considerados como critérios de inclusão, estar devidamente matriculado nas disciplinas em algum dos quatro semestres entre os anos de 2009 e 2010 e ter finalizado a disciplina independente do aproveitamento final. Para a realização do estudo os alunos foram esclarecidos quanto aos objetivos da pesquisa e assinaram o Termo de Consentimento Livre e Esclarecido os que aceitaram voluntariamente participar da pesquisa. Participaram da pesquisa 650 alunos, sendo 530 de graduação e 120 de pós-graduação.

A coleta de dados se deu utilizando dados quantitativos e qualitativos, dentro do enfoque formativo. Рага os dados quantitativos foi aplicado o questionário padrão utilizado pelo Centro de Promoção de Eventos (CESPE) da UnB com um instrumento dividido em duas partes; a primeira parte avalia a qualidade do ensino na disciplina (qualidade e quantidade do acervo da biblioteca, suporte técnico, assistência dos monitores, número de tutores, tempo dedicado ao acompanhamento tutorial, entre outros) e, a segunda parte, a qualidade do conteúdo ministrado (fixação de conteúdos, clareza da exposição, aplicabilidade dos conteúdos ministrados à futura profissão, todos esses itens fazendo a comparação entre o ensino presencial e a distância. Além disso, utilizamos a observação direta e os registros das atividades das disciplinas.
Para a análise estatística dos dados quantitativos foi utilizado Software Statistical Package for Social Sciences (SPSS) versão 17.0, com objetivo de obter as frequências dos dados alimentados por meio dos questionários. As informações qualitativas foram analisadas a partir dos dados da observação direta dos processos desenvolvidos nas disciplinas e organizadas em tópicos descritivos.

Este estudo foi aprovado pelo Comitê de Ética em Pesquisa com Seres Humanos da Faculdade de Ciências da Saúde (FS) da UnB sob o número do Parecer $177 / 2009$, tendo os participantes assinado o Termo de Consentimento Livre e Esclarecido e concordado em participar do estudo.

\section{RESULTADOS E DISCUSSÃO}

\section{As disciplinas de graduação e pós-graduação em saúde: os casos de moodle-fólios}

A UnB normatizou que todos os docentes devem no primeiro dia de aula disponibilizar aos alunos matriculados o planejamento das disciplinas sob sua supervisão. Os alunos foram informados sobre a utilização do Moodle-fólio e acerca de sua importância para o registro das atividades que serão desenvolvidas durante todo o processo educativo. Foi solicitado aos alunos que se cadastrassem no ambiente http://aprender.unb.br, na ocasião do primeiro acesso a plataforma de ensino. Após o cadastramento dos alunos, eles foram inseridos no espaço do Moodle-fólio onde participariam de todas as atividades planejadas.

Esse momento pedagógico foi aproveitado para reafirmar aos alunos os objetivos da proposta de registro e acompanhamento das atividades - o Moodle-fólio. Esta corrobora com os objetivos educacionais de: motivar os alunos menos capazes ao fornecer-lhes algo para mostrar por seus esforços, permitindo outra forma de avaliação; oportunizar aos alunos identificarem-se, acompanharem os registros de todos os envolvidos; refletir sobre as experiências vivenciadas; reconhecer resultados e êxitos além do domínio acadêmico; e, evidenciar as competências do aluno e dos envolvidos $(5,11)$.

\section{O moodle-fólio nos estudos de casos em questão}

O planejamento didático das disciplinas aqui analisadas foi fundamentado nos princípios da andragogia e da criatividade. O enfoque andragógico 
propõe como eixos orientadores para sua aplicabilidade no processo de ensino aprendizagem os seguintes princípios: avaliar suas capacidades pessoais como educador; compreender a situação global em que o processo educacional se insere; saber colocar-se no lugar do aluno; escolher os métodos mais eficazes para a situação; aprender a transmitir conhecimentos a um grupo; preparar e montar um ambiente adequado para a instrução; controlar a eficácia didática da instrução; conhecer e aperfeiçoar-se na didática para adultos (andragogia) ${ }^{(1,8)}$.

Dentre os critérios da criatividade, considerando as potencialidades do ser humano, os estudos destacam: sensibilidade aos problemas; estado de receptividade; mobilidade; originalidade; atitude para transformar e redeterminar; análises; sínteses; e, organização

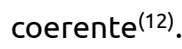

A aplicação desses critérios e concepções na prática com os Moodle-fólios implica a necessidade de resgatar a importância da avaliação, da democratização do saber, da autonomia que o espaço de ensino e aprendizagem oportuniza, para a construção, por meio das reflexões produzidas, das parcerias e da relevância dada ao uso da criatividade e do lúdico, levados a sério ${ }^{(1,12)}$. Isto porque, o trabalho do professor, que ensina, é também do professor, que aprende, pois seu trabalho não é apenas para transmitir o que sabe, mas requer um estar aberto para aprender o que não sabe.

\section{Design para o processo de ensino-aprendizagem}

A proposta de utilizar o Moodle-fólio como ferramenta para o acompanhamento de do planejamento didático das disciplinas avaliadas, se constituiu como uma iniciativa que envolveu alguns docentes do Departamento de Enfermagem e pesquisadores colaboradores do LEPS - UnB. Isso é devido ao novo currículo proposto para o curso de enfermagem estar em implantação a partir do período 1.2009 e pelo fato de que os cursos da área de saúde ainda utilizam modelos tradicionais, fundamentados nas diretrizes para o ensino dos cursos dessa área, mantendo-se conservadores e estruturados de forma a atender fundamentos meramente legalistas em detrimento de uma formação mais generalista, crítica e reflexiva, que tem respaldo na nova legislação.

O modelo de avaliação para os cursos implementados pela UnB segue uma proposta que possui um olhar interno para as questões do ensino, mas sem uma análise global por seus pares, carecendo de um olhar externo. A ausência do olhar externo torna a avaliação um mero preenchimento de papeis, pois os resultados são devolvidos ao professor sem um debate prévio por curso ou institucional.

\section{O design do Moodle-fólio para as avaliações nos estudos de casos}

\section{Pressupostos e fundamentos filosófico-educacionais}

Toda e qualquer ação educativa é precedida por pressupostos filosófico-educacionais, lógicos, epistemológicos, ontológicos e metodológicos que dão sentido ao processo de construção do conhecimento e de sua concreção na prática. Ao buscar nas novas tecnologias uma mediação didática para a transformação da prática educativa, intencionamos construir uma ação configurada em uma práxis dialógica, um agir comunicativo entre professores e alunos que viabilize a interação dialética entre a teoria e prática, problematize o saber, contextualize os conhecimentos e proporcione o resgate do papel dos alunos como sujeitos ativos, autônomos e co-autores no processo coletivo e cooperativo do conhecimento.

A concreção dessa prática exige uma transformação no sentido de uma ruptura com os tradicionais paradigmas da simplificação, permeados pela racionalidade técnica que, em geral, tem norteado a prática de ensino, configurando-a como uma atividade instrumental, uma mera transferência de conhecimentos centrada na primazia dos meios sobre os fins, da teoria prescritiva sobre a prática, no falar e no ditar por parte dos docentes e na recepção passiva, de fórmulas prontas e conhecimentos acabados, por parte dos alunos.

Conscientes da necessidade de superação dessa situação, os pressupostos e fundamentos que norteiam os referido casos encontram-se na confluência dos princípios científico-filosóficos propostos pela epistemologia da ciência crítica social e dialética e a teoria da complexidade, que sustenta as tendências educativas críticas. Sob essa perspectiva, a concepção de educação fundamenta-se, sobretudo para uma educação como ação comunicativa e dialógica ${ }^{(1-4,13)}$, resgatando a pesquisa como princípio educativo e a integração dialética da qualidade política e técnicas nos diferentes momentos da produção do conhecimento(12-14). 
A educação é, portanto, concebida, como uma prática de comunicação, de liberdade e de conscientização, situada historicamente e configurada como ação comunicativa, dialógica, coletiva, participativa e colaborativa, conectada com os ideais emancipatórios. Configura-se nessa práxis educativa a visão holística e planetária do homem, mundo e sociedade e a articulação pensamento-ação, gerando a relação dialética entre teoria-prática e ensino-pesquisa ${ }^{(1,5,8-9,11)}$.

Nesse cenário, os recursos tecnológicos - utilizados nas disciplinas e que contribuem para sua virtualização são encarados como mediadores no processo de ensinoaprendizagem. Assim, para além da visão tecnicista que os encara como instrumentos neutros e autônomos, os concebemos como tecnologias da inteligência, sendo ferramentas geradoras de conhecimento e cultura que contribuem para determinar modos de percepção e intelecção pelo qual conhecemos os objetos e que podem fornecer modelos teóricos para as formas de concebermos, racionalmente a realidade ${ }^{(12)}$.

A visão crítica sobre o sentido e papel das tecnologias, para fins de projetos educacionais, como se tem enfatizado, é imprescindível para a superação das consciências acríticas e ingênuas decorrentes, sobretudo, do pensamento fragmentado, da visão tecnocrática e do fascínio e discurso apologético das técnicas que acabam gerando vieses e desvirtuando os fins educacionais $(8,10)$. Portanto, nunca é demais insistir que as técnicas, por elas mesmas, não obstante todo seu potencial, não garantem a inovação e as transformações educacionais almejadas.

Verificamos que esses pensamentos são refletidos no estudo de caso em questão, ao adotar-se uma metodologia baseada em oficinas virtuais que constituem o núcleo da estrutura curricular das disciplinas. Nessas oficinas são contemplados dinâmicas de trocas de convivências, símbolos e significados, provocando a curiosidade e o prazer para um processo de auto e hetero conhecimento, assim como para a construção conjunta do saber.

Do ponto de vista didático, as oficinas são encontros pedagógicos - muito utilizados no ensino presencial - que promovem uma prática educativa colaborativa, instigando a interatividade, a interdisciplinaridade e o espírito científico assim como o comprometimento com a melhoria e transformação da realidade. Permeadas, em geral, pelo lúdico, tornam a ação educativa agradável, em seus diferentes momentos, para a construção, elaboração, reflexão e aplicação do marco conceitual, atingindo o domínio das dimensões do ser humano, sem, contudo, desviar os compromissos com a seriedade científica na construção do conhecimento(12).

\section{Disciplinas avaliadas}

As disciplinas foram ofertadas na modalidade optativa para graduação e pós-graduação, sendo uma das disciplinas de graduação ofertada na modalidade de módulo livre. Todos os alunos matriculados estavam cientes do comprometimento com a proposta e metodologia da disciplina, da utilização da internet para a realização das atividades dentro de prazos e quanto as frequências obrigatórias nos encontros presenciais.

No desenho instrucional devem estar claras as orientações das atividades, em consonância com os princípios filosóficos e políticos que norteiam o conteúdo proposto. Assim sendo, a proposta pedagógica incluiu como desenho instrucional as seguintes atividades educativas:

a) Encontros presenciais: a proposta previa, no mínimo, três encontros presenciais, cujo objetivo seria a orientação didático-pedagógica para os alunos matriculados nas disciplinas dos casos em estudo.

b) Módulos instrucionais: constituem as unidades temáticas que foram trabalhadas em cada momento dos casos em estudo. Em média, cada caso teve cinco módulos instrucionais, contemplando um conjunto de conteúdos a serem aprofundados no decorrer das atividades propostas para a aquisição de conhecimentos, habilidades e atitudes.

c) Salas de leituras: são espaços disponibilizados em cada um dos estudos de casos analisados, onde ficam postadas as referências bibliográficas consideradas essenciais à compreensão do módulo.

d) Fórum de notícias: bloco de notícias onde docentes e tutores informam a todos os participantes a respeito dos cursos, encontros presenciais, eventos e orientações didáticas, sendo inseridas individualmente e quando recomendadas.

e) Fóruns de sistematização: os fóruns são espaços para reflexões e sínteses construídas coletivamente. Em alguns fóruns são orientados debates sobre textos e filmes relacionados aos módulos instrucionais.

f) Atividades de sistematização: nessas atividades são postados os trabalhos elaborados individualmente, como 
resenhas críticas de textos e filmes e projetos construídos individualmente.

g) Mensagens reservadas: o Moodle oferece a opção de enviar mensagens, favorecendo a comunicação com todos os envolvidos no processo educativo de forma reservada.

h) Mensagens coletivas: é também possível enviar mensagens a todos os envolvidos no processo ou para um grupo selecionado.

i) Bate-papos: incluímos os espaços de bate-papo. Segundo a análise de nossas experiências, são espaços que não têm contribuído para a comunicação entre o grupo.

j) Netiqueta: elaboramos um Código de Postura para os participantes do processo educativo, com itens que foram construídos coletivamente. Também apresentados no primeiro encontro presencial e acordado para sua implementação, servindo como um contrato de postura assumido por todos.

k) Sala do cafezinho: disponibilizamos esta opção para todos postarem notícias que considerarem importantes e/ou que contribuam para ampliação das informações dos participantes em cada estudo de caso analisado.

\section{As disciplinas na opinião dos alunos}

Para trazermos a perspectiva dos alunos acerca das disciplinas apresentamos o perfil dos participantes na Tabela 1.

Tabela 1: Distribuição dos alunos por idade, sexo, nível de ensino, LEPS. Brasília, DF, 2009-2010.

\begin{tabular}{|c|c|c|c|c|c|c|c|c|}
\hline \multirow{3}{*}{ Idade } & \multicolumn{4}{|c|}{ PG $2009-2010$} & \multicolumn{4}{|c|}{ GR 2009 - 2010} \\
\hline & \multicolumn{2}{|c|}{ Masculino } & \multicolumn{2}{|c|}{ Feminino } & \multicolumn{2}{|c|}{ Masculino } & \multicolumn{2}{|c|}{ Feminino } \\
\hline & $\mathbf{N}$ & $\%$ & $\mathbf{N}$ & $\%$ & $\mathbf{N}$ & $\%$ & $\mathbf{N}$ & $\%$ \\
\hline 18 a 25 anos & 08 & 6,67 & 16 & 13,33 & 162 & 30,6 & 198 & 37,36 \\
\hline 26 a 35 & 10 & 8,33 & 22 & 18,33 & 26 & 4,91 & 56 & 10,57 \\
\hline 36 а 45 & 11 & 9,17 & 20 & 16,67 & 32 & 6,04 & 30 & 5,66 \\
\hline 46 a 55 & 10 & 8,33 & 14 & 11,67 & 10 & 1,89 & 16 & 3,02 \\
\hline Mais de 56 anos & 01 & 0,83 & 08 & 6,67 & 00 & 0 & 00 & 0 \\
\hline TOTAL & 40 & 33,3 & 80 & 66,67 & 230 & 43,4 & 300 & 56,6 \\
\hline
\end{tabular}

Legenda: PG - Pós-Graduação; GR - Graduação.

Em relação à caracterização sócio-demográfica, destaca-se que a amostra estudada foi constituída preponderantemente por estudantes do sexo feminino tanto na graduação quanto na pós-graduação, além de ter prevalecido ente os graduandos, em ambos os gêneros, a faixa etária 18 a 25 anos e nos pósgraduandos a faixa etária 36 a 45 anos no sexo masculino e 26 a 35 anos no sexo feminino.

Quando questionados sobre o uso do Moodle, todos os estudantes, para ambos os níveis de ensino envolvidos, informaram já o conhecerem como ferramenta utilizada no ensino, mas não como portfólio eletrônico.

Em relação ao tempo disponibilizado para o cumprimento das atividades, fóruns, participação em debates, encontros presenciais e respostas no Moodlefólio, no ensino de graduação, 238 (44,90\%) participantes dedicaram duas horas semanais em cada caso estudado. No ensino de pós-graduação, 32 (26,67\%) entrevistados demonstraram o mesmo tempo. Quando verificado os que dedicam mais de duas horas, 227 (42,8\%) estudantes são destacados no ensino de graduação; e, 63 (52,5\%) no ensino de pós-graduação. Outro dado que consideramos importante foi que 133 (25,09\%) dos alunos de graduação e 24 (20,00\%) dos de pós-graduação utilizaram o horário entre meia-noite e 06h00 diariamente para participarem das atividades programadas. No ensino de graduação, 223 alunos (42,07\%) e, 60 (50,00\%) no ensino de pós-graduação utilizaram o Moodle-fólio no horário noturno, entre $18 \mathrm{~h} 00$ e $23 \mathrm{~h} 00$.

Os achados relacionados ao gênero predominante, a faixa etária, as horas de estudo e ao horário preferido para estudar, foram semelhantes aos identificados em outras pesquisas que avaliaram alunos de graduação, pós-graduação e capacitação na área da saúde inseridos na $E A D^{(15-16)}$ e reforçam a afirmação que aprendizagem a distância vem aumentando as chances educativas dos 
adultos, possibilitando à aprendizagem a qualquer hora e em qualquer lugar ${ }^{(17)}$.

Outro aspecto analisado, a avaliação do processo de aprendizagem, destaca que os estudantes, de graduação
(GR) e pós-graduação (PG) classificaram como: Muito Bom (MB); Bom (BO); Regular (RE); Ruim (RU). O Gráfico 1 ilustra esse dado.

Gráfico 1: Uso do moodle-fólio no processo de ensino aprendizagem, nível de formação, 2009-2010.

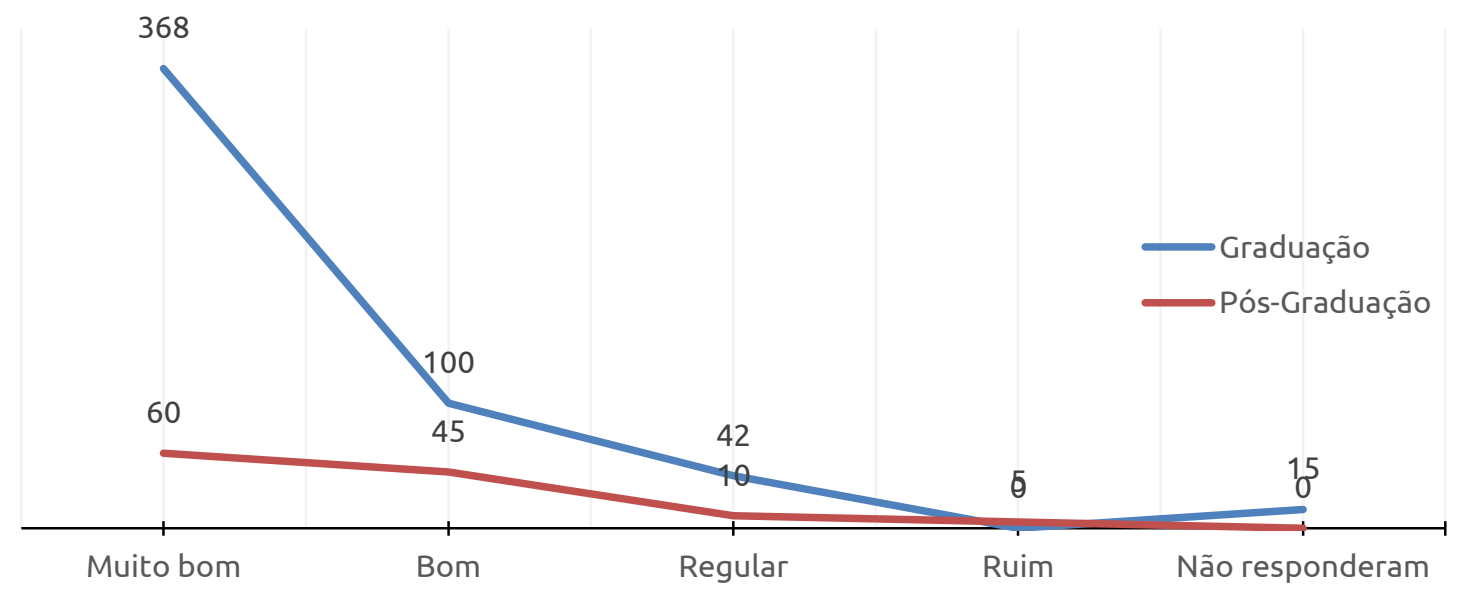

Ao considerar a totalidade dos alunos de graduação e pós-graduação observa-se uma preponderância dos alunos no item Muito Bom (65,85\%) seguido o item Bom (22,31\%), caracterizando um importante achado que remonta a qualidade do Moodle-fólio, uma vez que estudos têm revelado que a satisfação do usuário com o processo educacional influencia a transferência do conhecimento, predizendo o impacto do evento educativo na vida profissional(18).
Quanto à utilização do design instrucional nos casos estudados, apresentamos três categorias: 1) a dos momentos de encontros presenciais e bate-papos; 2) a relacionada aos materiais instrucionais e metodologias utilizadas e 3) as relacionadas à organização e administrativas. Ilustraremos esses dados em tabelas, iniciando pela Tabela 2, que traz os dados relativos aos encontros presenciais.

Tabela 2: Avaliação do design instrucional: encontros presenciais, chats e netiqueta. UnB. Brasília, DF, 2010.

\begin{tabular}{|c|c|c|c|c|}
\hline \multirow{2}{*}{ Níveis } & \multicolumn{2}{|c|}{ Graduação } & \multicolumn{2}{|c|}{ Pós-Graduação } \\
\hline & $\mathbf{N}$ & $\%$ & $\mathbf{N}$ & $\%$ \\
\hline \multicolumn{5}{|l|}{ 1. Encontros presenciais } \\
\hline Muito bom & 169 & 31,89 & 89 & 74,16 \\
\hline Bom & 173 & 32,64 & 20 & 16,66 \\
\hline Regular & 108 & 20,37 & 10 & 08,33 \\
\hline Ruim & 080 & 15,10 & 01 & 00,83 \\
\hline \multicolumn{5}{|l|}{ 2. Chats } \\
\hline Muito bom & 187 & 32,28 & 60 & 50,00 \\
\hline Bom & 177 & 33,39 & 30 & 25,00 \\
\hline Regular & 106 & 20,00 & 15 & 12,50 \\
\hline Ruim & 060 & 11,32 & 15 & 12,50 \\
\hline \multicolumn{5}{|l|}{ 3. Netiqueta (regras de convivência) } \\
\hline Muito bom & 333 & 62,83 & 78 & 65,00 \\
\hline Bom & 197 & 37,17 & 22 & 18,33 \\
\hline Regular & 000 & 00,00 & 10 & 8,33 \\
\hline Ruim & 000 & 00,00 & 10 & 8,33 \\
\hline Itens avaliados & 530 & 100 & 120 & 100 \\
\hline
\end{tabular}


Como podemos observar 342 (64,53\%) estudantes da graduação e 109 (90,83\%) de pós-graduação, consideraram os encontros presenciais entre muito bom e bom.

Os bate-papos (chats) foram indicados como muito bom e bom entre 364 (68,68\%) estudantes da graduação e $90(75,00 \%)$ da pós-graduação. Quando analisado o item netiqueta, os dados demonstram que 530 (100\%) estudantes da graduação e 100 (83,33\%) da pósgraduação consideraram-no também muito bom e bom.

Na Tabela 3, foram analisados os aspectos relacionados aos materiais instrucionais elaborados e a metodologia proposta na utilização dos Moodle-fólios.

Tabela 3: Avaliação do design instrucional: módulo instrucional, salas de leitura e atividade de sistematização, UnB. Brasília, DF, 2010.

\begin{tabular}{|c|c|c|c|c|}
\hline \multirow{2}{*}{ Total de itens } & \multicolumn{2}{|c|}{ Graduação } & \multicolumn{2}{|c|}{ Pós-Graduação } \\
\hline & $\mathbf{N}$ & $\%$ & $\mathbf{N}$ & $\%$ \\
\hline \multicolumn{5}{|l|}{ 1. Módulos instrucionais } \\
\hline Muito bom & 310 & 58,49 & 90 & 75,00 \\
\hline Bom & 120 & 22,64 & 15 & 12,50 \\
\hline Regular & 065 & 12,26 & 10 & 08,33 \\
\hline Ruim & 035 & 06,60 & 05 & 04,17 \\
\hline \multicolumn{5}{|l|}{ 2. Salas de Leituras } \\
\hline Muito bom & 350 & 66,04 & 85 & 70,83 \\
\hline Bom & 120 & 22,64 & 35 & 29,17 \\
\hline Regular & 060 & 11,32 & 00 & 00,00 \\
\hline Ruim & 000 & 00,00 & 00 & 00,00 \\
\hline \multicolumn{5}{|l|}{ 3. Atividades de sistematização } \\
\hline Muito bom & 303 & 57,16 & 93 & 77,50 \\
\hline Bom & 227 & 42,84 & 08 & 06,67 \\
\hline Regular & 000 & 00,00 & 09 & 07,50 \\
\hline Ruim & 000 & 00,00 & 10 & 08,33 \\
\hline Itens avaliados & 530 & 100 & 120 & 100 \\
\hline
\end{tabular}

Com relação aos módulos instrucionais, tanto os 310 alunos de graduação $(58,49 \%)$, quanto os 90 de pósgraduação (75\%) consideram como muito bom a utilização deste recurso. Com relação as salas de leituras, 350 (66,04\%) alunos de graduação e 85 (70,83\%) alunos de pós-graduação também as consideraram como muito bom. As atividades de sistematização foram analisadas por 303 (57,16\%) alunos de graduação e 93 (77,50\%) alunos de pós-graduação como muito bom. 
Tabela 4: Avaliação do design instrucional: fóruns e mensagens, UnB, Brasília, DF, 2010.

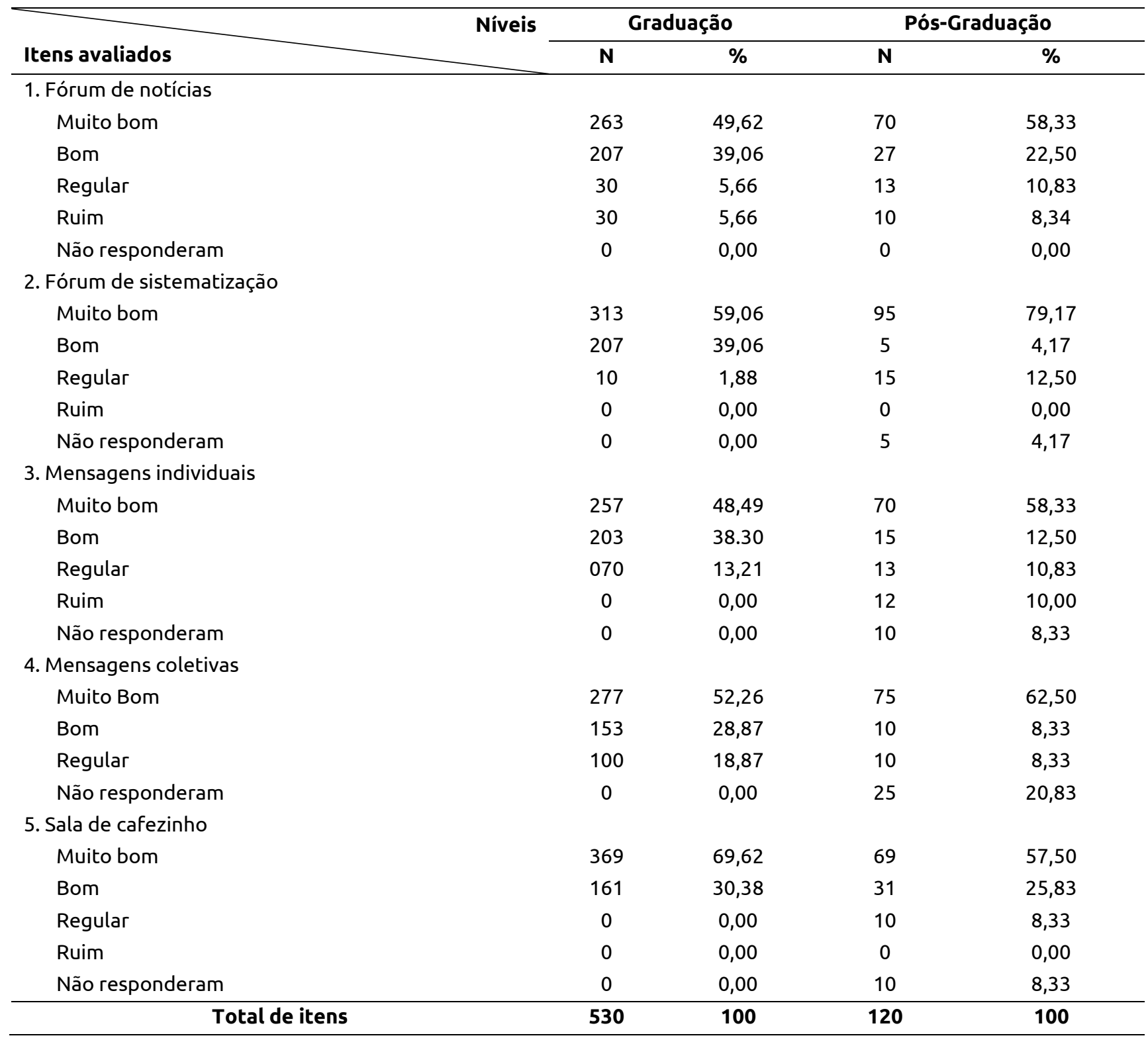

Como se pode observar na Tabela 4, os fóruns de sistematização para $95(79,17 \%)$ estudantes de pósgraduação e as salas de cafezinho (fórum livre) para 369 $(69,62 \%)$ estudantes de graduação, compreendem os meios mais valorizados, por sua importância no uso dos Moodle-fólios no processo de aprendizagem. Similar situação ocorre com a importância atribuída as mensagens coletivas, onde 277 (52,26\%) dos estudantes de graduação e 75 (62,50\%) dos estudantes de pósgraduação as consideram como a forma de comunicação onde a maioria dos estudantes recebe notícias, orientações e se comunicam entre si.

Estudos que avaliaram o design instrucional de disciplinas inseridas em AVA, na perspectiva dos estudantes, também demonstram uma reação satisfatória a estratégias de aprendizagem auxiliadas pelas TIC (chats, mensagens eletrônicas individuais/coletivas, fóruns etc), a momentos presenciais e a utilização de código de convivência que facilite a expressão de ideias no ambiente da disciplina (netiqueta) ${ }^{(15,19) .}$

Nesta perspectiva, a utilização de Moodle-fólios demonstrou sua importância, pois se constituem em pontos de encontros coletivos para os registros dos processos de ensino-aprendizagem vivenciados num determinado contexto e dos seus produtos. Estudos apontam esta proposta como uma tendência semelhante à concepção dos webfólio, como uma espécie de dossiê que privilegia as melhores produções dos sujeitos(5-6,9-10).

Tendo em vista a franca expansão da EAD no ensino de graduação e pós-graduação em instituições públicas e privadas brasileiras ${ }^{(20)}$, ao analisar o Moodle-fólio, 
percebemos que tal ferramenta pode contribuir muito para o processo de ensino-aprendizagem na EAD, tornando-se ótimo apoio pedagógico para a avaliação formativa, com um envolvimento mais coletivo, democrático, transparente e justo.

Apesar das inúmeras vantagens descritas até o momento, também existem alguns desafios, principalmente, pelo fato de não haver uma cobrança do docente como no modelo convencional, mas sim uma gestão participativa do processo educativo no uso do Moodle-fólio, que apesar de ser um desafio, pode facilitar a visualização dos avanços de todos na aprendizagem e os obstáculos que resultam em dificuldades ou impedimentos para a criação de oportunidades inovadoras no ensino universitário. Neste espaço, estão reunidos todos os registros e documentos das atividades que orientam ao estudante o que fazer.

\section{CONCLUSÃO}

Os Moodle-fólios permitiram o acompanhamento, dentro de um enfoque avaliativo formativo, para um repensar do processo de aprendizagem de todos envolvidos, ao mesmo tempo em que serviram à produção de conhecimentos, possibilitando uma aproximação real da teoria e da prática vivenciada em diferentes espaços pedagógicos.

O uso do Moodle-fólio foi considerado importante quanto aos seus diferentes itens avaliados no acompanhamento do processo ensino-aprendizagem. Tomado em seu conjunto, a avaliação do Moodle-fólio, revela um significativo grau de satisfação, compromisso e seriedade, por parte dos estudantes, sobre a forma como o mesmo foi utilizado e sobre suas contribuições teórico-práticas para o enriquecimento dos futuros profissionais participantes.

Assim, essa pesquisa comprometida com as transformações futuras, busca, sob o olhar prospectivo, oferecer subsídios teórico-práticos para a revisão ou construção do uso dessa ferramenta para os novos cursos e encaminhamentos para tomadas de decisões rumo à melhoria do processo acadêmico, e nesse âmbito, para os programas de expansão da educação do ensino em saúde.

12. Candau VM et. al. Oficinas pedagógicas de direitos humanos. Petrópolis: Vozes; 1995.

13. Habermas J. Teoría de La acción comunicativa: La racionalidad de La acción y racionalización social. Madrid: Taurus. 1988.

14. Levy P. A inteligência coletiva. São Paulo: Loyola; 1998. 15. Peixoto HM. Avaliação de disciplinas semipresenciais de graduação e pós-graduação na área de promoção da saúde na Universidade de Brasília [dissertation]. Brasília: Departamento de Enfermagem/UnB; 2012. 91 p.

16. Alves ED, Kusano MSE, Serpa MGN, Kusano LME, Quaresma M. Añejos y avances en la utilizacion de la internet para la enseãnanza superior de enfermería en el Brasil. Revista Panamericana de Enfermeria. 2004;2(1):14-23.

17. Abbad GS, Zerbini T, Souza DBL. Panorama das pesquisas em educação a distância no Brasil. Estud. psicol. (Natal) [Internet]. 2010 [cited 2012 sep 30];15(3):291-8. Available from: http://dx.doi.org/10.1590/S1413-294X2010000300009.

18. Zerbini T, Abbad G. Reações em cursos a distância: revisão da literatura. Psico (Porto Alegre) [Internet]. 2010 [cited 2012 sep 30];41(2):192-200. Available from: http://revistaseletronicas.pucrs.br/ojs/index.php/revistapsico/articl e/viewFile/5354/5313.

19. Laguardia J, Casanova A, Machado R. A experiência de aprendizagem on-line em um curso de qualificação profissional em saúde. Trab. Educ. Saúde [Internet]. 2010 [cited 2012 sep 30];8(1):97-122. Available from: http://dx.doi.org/10.1590/S198177462010000100006.

20. Rodrigues RCV, Peres HHC. Panorama brasileiro do ensino de Enfermagem On-line. Rev Esc Enferm USP [Internet]. 2008 [cited 2012 sep 30];42(2):298-304. Available from: http://dx.doi.org/10.1590/S0080-62342008000200013.

Artigo recebido em 27/01/2012.

Aprovado para publicação em 28/06/2012.

Artigo publicado em 30/09/2012. 